\title{
Erratum to: Statistical study to identify the key factors governing ground water recharge in the watersheds of the arid Central Asia
}

\author{
Bing-Qi Zhu • Yue-Ling Wang
}

Published online: 7 March 2016

(C) Springer International Publishing Switzerland 2016

Erratum to: Environ Monit Assess (January 2016)

188, Issue 1:66

DOI 10.1007/s10661-015-5075-4

The original version of this article unfortunately contained an error and omitted two foundations.

The name of the first author should have been Bing-Qi Zhu not Binq-Qi Zhu. The corrected author name is shown above.

Two foundations should have been included into the acknowledgment section. They are given below.

The study was also funded by the National Natural Science Foundations of China (grant nos. 41225001 and 41271049).

The online version of the original article can be found at http://dx. doi.org/10.1007/s10661-015-5075-4.

B.-Q. Zhu $(\bowtie) \cdot$ Y.-L. Wang

Key Laboratory of Water Cycle and Related Land Surface Processes, Institute of Geographic Sciences and Natural Resources Research, Chinese Academy of Sciences, Datun Road, No. A11, Chaoyang District, Beijing 100101, China

e-mail: zhubingqi@igsnrr.ac.cn 